Int. J. Dev. Biol. 50: 267-275 (2006)

doi: $10.1387 / \mathrm{ijdb} .052061 \mathrm{yk}$

\title{
Morphomechanical programming of morphogenesis in Cnidarian embryos
}

\author{
YULIA A. KRAUS* \\ Dept. of Evolutionary Biology, Biological Faculty, Moscow State University, Moscow, Russia
}

\begin{abstract}
The factors governing the pattern formation process in the early morphogenesis of a marine colonial hydroid, Dynamena pumila, have been studied. Two different types of morphogenesis have been distinguished. Morphogenesis of the first type goes on via changes in cell shape and cell axis orientation, while morphogenesis of the second type is based upon the active coordinated cell movements associated with cell rearrangements. It was shown that morphogenesis of both types can be considered as cascades in which any event is a consequence of the previous one. The spatial structure of each developmental stage contains information about the direction and the initial conditions of further morphogenesis. So, an "epigenetic program" of morphogenesis gradually originates in the course of development and provides the stable reproduction of spatial structures. It is reasonable to consider the activity of epigenetic factors guiding Dynamena morphogenesis (geometry/topology of an embryo, heterogeneity of an embryo spatial structure, configuration of the field of mechanical stresses of the embryo surface) as "morphomechanical programming" of morphogenesis.
\end{abstract}

KEY WORDS: embryonic development, Hydrozoa, morphogenesis, epigenetic factor, developmental pathway

\section{Introduction}

During the past two decades the majority of investigations dealing with pattern formation in embryogenesis have been focussed on the genetic aspects of this problem. As a result, we have a vast collection of data describing the spatiotemporal regulation of gene expression during the development of different organisms (for review see Wilkins, 2001). However, it is difficult to imagine how the three-dimensional structure of an embryo is regulated by genetic pathways alone. Furthermore, recent works on molecular mechanisms of embryonic development and cell differentiation have shown the context-dependency of gene expression and function (Galbraith and Sheetz, 1998; Wray and Abouheif, 1998; Chiquet, 1999; Eizinger et al., 1999; Gilbert and Sarkar, 2000; Grbic, 2000; Wu et al., 2001; Kirwan et al., 2004; Tian etal., 2004). These are the main reasons for current changes in the approach to understanding the role of epigenetic factors in development, differentiation and evolution of morphological features (Gilbert and Sarkar, 2000; Goodwin, 2000; Newman and Muller, 2000; Wilkins, 2001; Strohman, 2002). Indeed, it is reasonable to take into consideration the epigenetic factors which definitely operate in three-dimensional space (geometry and mechanical properties of embryonic tissues, heterogeneity of an embryo, asymmetry of external environment, laws of self-organiz- ing biochemical networks etc.) as additional (not alternative) sources of developmental control (Arnolds et al., 1983; Oster et al., 1983; Belintsev, 1991; Beloussov et al., 1994; Beloussov, 1996, 1998; Kropf etal., 1999; Coffman etal., 2001; Gilbert, 2001; Davidson et al., 2002; Keller et al., 2003). The problem is that in the ontogeny of higher Metazoan animals the genetic and epigenetic regulatory pathways are so intimately connected with each other that it is very difficult to separate their effects. Epigenetic factors are of special importance for providing stable ontogenetic reproduction of newly evolved morphological structures «prior to the biochemical canalization of developmental pathways and the stabilization of phenotype» (Newman and Muller, 2000; see also Cherdantsev et al., 1996). It is possible that epigenetic factors play a similar role in embryonic development of low Metazoan animals that preserve the morphogenetic pathways and patterning mechanisms close enough to the earliest evolutionary morphogenetic pathways.

Cnidaria, being lower Metazoan animals, possess a simple and evolutionarily primitive body plan and are thus quite attractive for investigations of the epigenetic factors that might regulate patterning during embryogenesis. The diversity of Cnidarian

Abbreviations used in this paper: $\mathrm{AB}$ axis, apico-basal cell axis; ESF , epithelial sheet fragment; SEM, scanning electron microscopy.

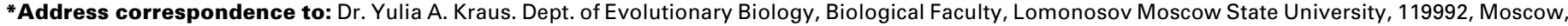
Russia. Fax: +7-495-939-4309. e-mail: yulia_kraus@hydrozoa.org
} 

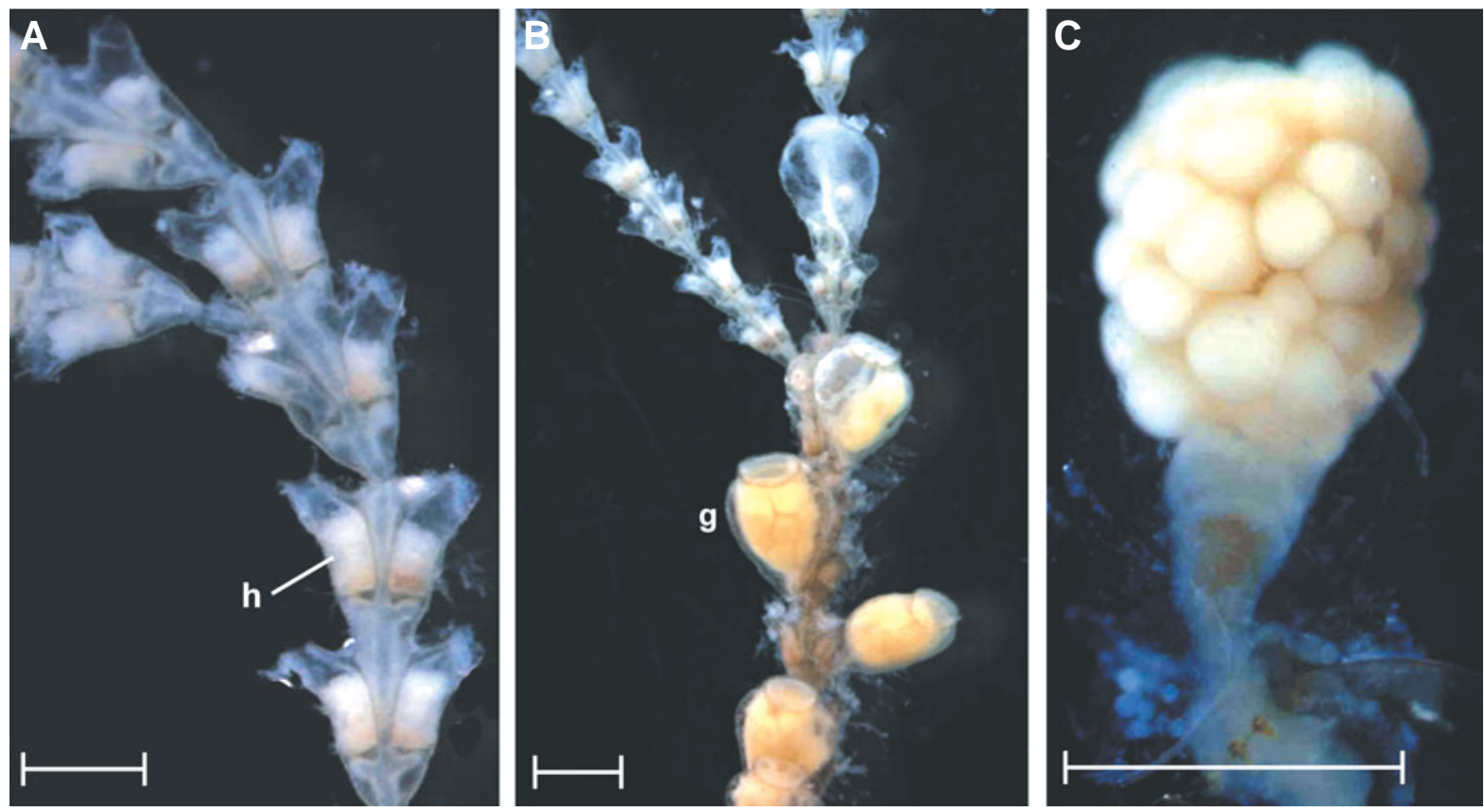

Fig. 1. Dynamena pumila colony. (A) Colony fragment (h-hydrant hiding inside the hydrotheca). (B) Colony with the gonothecae (g) containing immature eggs. (C) Acrocyst with developing embryos. Scale bars, $1 \mathrm{~mm}$.

developmental pathways is extremely high (Metshnikoff, 1886). This diversity seems to be degenerate in the sense that different pathways converge to a fundamentally simple and invariant body plan of a planula larva, the final stage of Cnidarian embryogenesis that can be considered as a phylotypic stage (Raff, 1996) of this phylum.

The planula has an axis of anterioposterior polarity and consists of two epithelial cell layers, the ectoderm and endoderm. As a rule, the planula larva develops into a polyp - a sessile stage of the Cnidarian life cycle.

The purpose of the investigation presented here is to demonstrate the role of epigenetic factors in the embryonic development of a White Sea colonial hydroid polyp Dynamena pumila L. (Hydrozoa, Sertulariida) (Fig. 1A).

\section{Normal development of Dynamena pumila}

Dynamena embryogenesis has already been described in great detail (Kraus, Cherdantsev, 1995, 1999, 2003), nevertheless, normal development of this species should be portrayed here in brief.

Dynamena pumila does not form free living medusae. Eggs are differentiated within the tissues of specialized polyps (gonangia) surrounded by the gonotheca (Fig. 1B). After the eggs are completely formed, the acellular mucous acrocyst, which is produced by gonangium tissues, emerges from the gonotheca. Mature eggs are shed into the acrocyst; the number of eggs may vary from 4 to 24 . Embryos develop inside the acrocyst until the planula stage (Fig. 1C). Dynamenanormal development from the beginning of cleavage to planula larva takes about 72 hours.

Early development of Dynamena starts with irregular cleavage. The first cleavage furrow originates at the animal pole and passes through the egg along the animal-vegetal axis (Fig. 2A).
The second furrow may appear after or before the completion of the first one. In the first case the cleavage remains synchronous up to the 8-16 cell stage (Fig. 2B); in the second one cleavage immediately becomes irregular and strongly asynchronous (Fig. 2C). In both cases at the 32-64 cell stage the embryo becomes a morula whose characteristic features are the looseness of the packing of cells, the lack of segregation between the outer and inner cells and the lack of a regular shape (Fig. 2D, E). Because Dynamena embryos are tightly packed inside the acrocyst, in each embryo one can distinguish several flat surfaces that correspond to contact regions with the neighboring embryos (Fig. 2E).

Formation of the continuous superficial epithelial sheet is the main result in the hydroids which develop via the morula stage. The epithelial sheet allows isolation of the inner compartment of the organism from the external environment while maintaining the organism's tissue integrity and polarity. In Dynamena embryos only small epithelial sheet fragments (ESFs) consisted of 5-20 epithelial cells are formed at the first step of this process (Fig. $2 F, G)$. Formation of ESFs starts simultaneously in several regions of an embryo, primarily at the bending regions of the embryonic surface, i.e. at the circumference of a flat surface (Fig. $2 F, G, H, I)$. Not only superficial cells take part in epithelialization. The inner cells are involved in this process by forming «rosettes» including both superficial and inner cells (Fig. 2l).

At the next step of epithelial sheet formation the local ESFs are joined with each other. Protrusion and crawling activity of superficial epithelial cells is a driving force of this process. The active planar movements of Dynamena embryonic cells have been monitored using scanning electron microscopy starting from the morula stage. The moving cells develop leading and trailing edges in a manner similar to that of the isolated cell (Fig. 3A-D). It seems as if embryonic cells interpret any discontinuity in the epithelial sheet as a wound. They move to the 'wound margin' 
(ESF margin), extend filopodia towards the cells of the opposing fragment and establish cell-cell contacts at the filopodia tips (Fig. $3 \mathrm{~A}, \mathrm{~B})$. Contraction of the anchored filopodia brings together the margins of adjacent fragments. The final step of ESF joining sealing of the margins of two neighboring ESFs by overlapping lamellae of crawling cells - is presented on the Fig. 3C. Insofar as ESFs are formed primarily at the circumference of the flat surfaces, the joining of the neighboring ESFs creates a surface looking like a torus, or like a set of toroidal surfaces joined together (Fig. 4A). It is interesting to note that there is a close similarity between the Dynamena morphogenesis described above, mor-
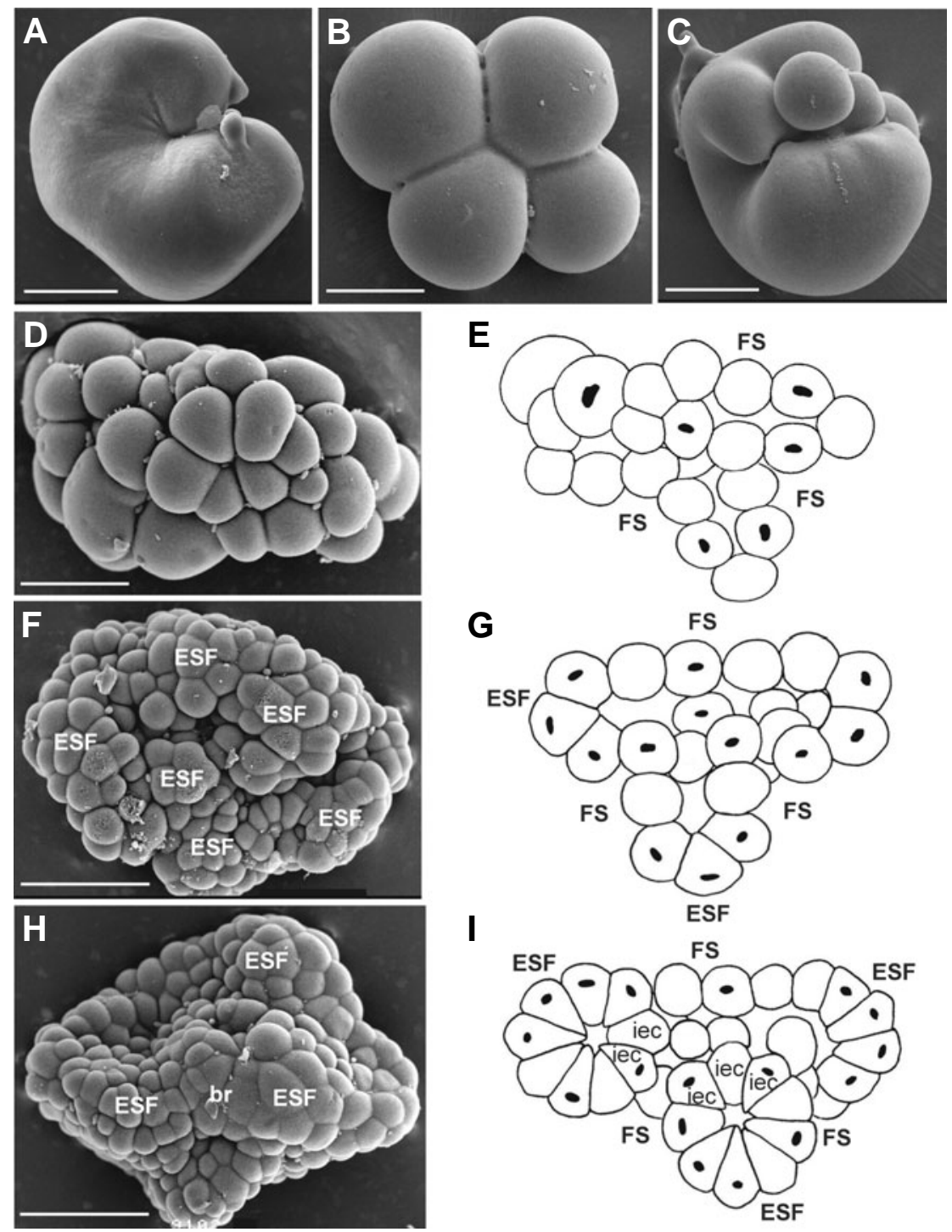

E

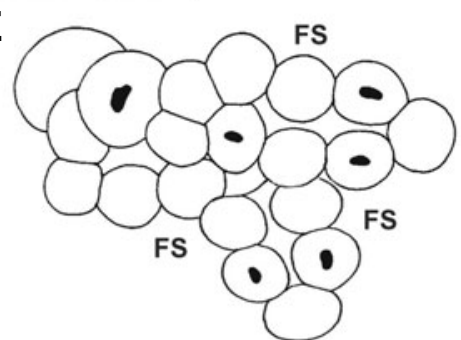

G

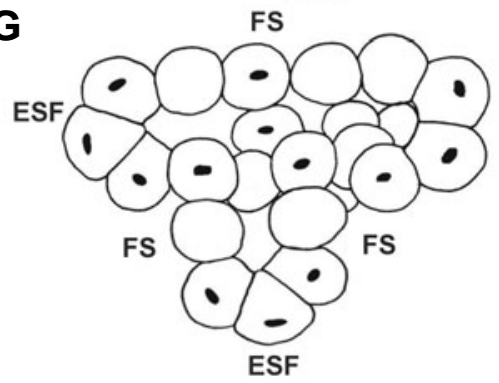

1

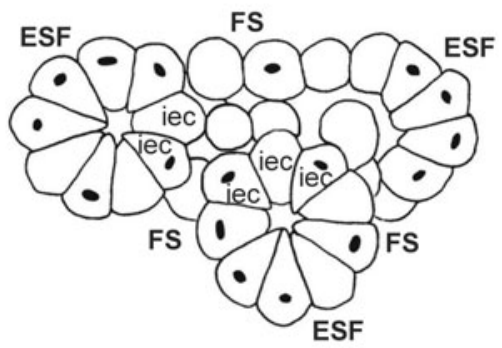

Fig. 2. Early cleavage, morula and epithelial sheet fragment formation (ESF) stages. (A) Formation of the first furrow. (B) Regular cleavage, 4-cell stage. (C) Irregular cleavage. (D) Early morula. (E) Schematic drawing of histological section of a morula (FS - flat surface). (F) An embryo having multiple ESFs, viewed from the flat surface. (G) An embryo at the beginning of ESF formation, schematic drawing of histological section. (H) An embryo at the stage of ESF formation, viewed from a bending region (br) of the embryonic surface. (I) Formation of epithelial 'rosettes' including both superficial and inner cells, schematic drawing of histological section (iec - inner epithelial cell). (A, B, C,D,F,H), SEM data. (E, G,I), taken from Kraus and Cherdantsev (1999), with modifications. Scale bars, $100 \mu \mathrm{m}$. phogenetic movements leading to the formation of continuous epithelial sheet in the embryos of high Metazoan animals, wound healing in adult and embryonic tissues and the process of contact Martin and Parkhurst, 2004; Vasioukhin and Fuchs, 2001; Jacinto and Martin, 2001). The 'active' mode of formation of intercellular contacts (Vasioukhin et characteristic feature of all these processes.

'Healing' of holes situated in the centers of toroidal surfaces proceeds at the next step of embryonic development in the same manner as the process of joining of ESFs (Fig. 4C). The morphology of the toroidal embryo and morphology of epithelial cells taking part in the process of hole healing are presented on the figures 4 A-D. It is interesting to note that moving epithelial cells do not lose their apico-basal polarity. They form leading and trailing edges at their apical surfaces preserving the shape that is specific for an epithelial cell (Fig. 4C, D).

Finally, toroidal embryos convert into the ellipsoidal ones (Fig. 8A). An elongation of the major axis of the ellipsoidal embryo, the morphological differentiation of its poles and the formation of the epithelial endoderm from the inner cells are the final steps of Dynamena embryonic development leading to planula formation (Fig. 8B).

\section{Morphogenesis of local epithelial sheet fragments}

It is possible to distinguish at least two types of morphogenetic processes in embryogenesis using as a key feature the main mode of cell behavior. Morphogenesis of the first type goes on via changes in cell shape and cell axis orientation. In this case the epithelial cells do not change their neighbors, so that any cell can change its position only due to the shaping of the embryonic surface as a whole. Morphogenesis of the second type is based upon active mutually coordinated cell movements when the cells change their neighbors, keeping their shapes more or less constant.

The formation of local ESFs in the early development of Dynamenais associated with morphogenesis of the first type. ESF formation is indeed a real morphogenesis. Each cell that joins an ESF gradually changes its shape in concert with the changes in the shape of an entire ESF (Fig. 5A).

It was already shown that epithelial morphogenesis in the tissues of Vertebrata embryos are based upon cooperative cell-to-cell interactions (Beloussov et al., 1974, 1975; Cherdantsev, 1977; Belintsev et al., 1987). These interactions are also responsible for the origin of local order of epithelial cells within an ESF in Dynamenaembryos (Kraus, Cherdantsev, 1999). This conclusion has been drawn from the following data:

1. A spatial sequence of cell shapes within a 

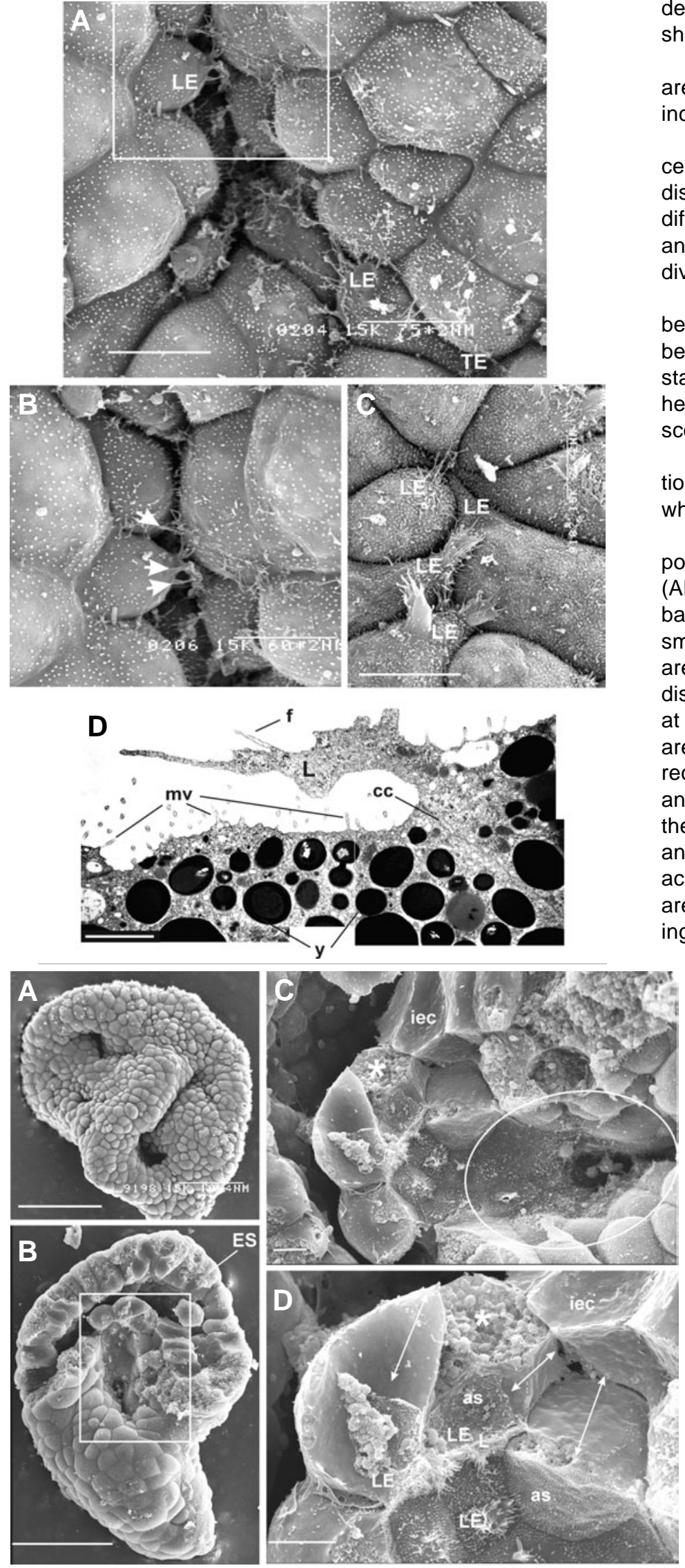

developing ESF corresponds to the successive stages of cell shaping during epithelialization (Fig. 5A, B, C).

2. Not only superficial cells become epithelial. The inner cells are involved in the epithelialization too, so that an ESF may include both superficial and inner cells (Fig 2I, 4C).

3 . The formation of local ESFs is an extremely variable process: the embryos differ from each other in the number and disposition of the developing ESFs and ESFs of a same embryo differ in the number of cells involved. Therefore, both the shape and the internal structure of individual embryos exhibit a maximal diversity and each embryo has a unique shape at this stage.

4. Any heterogeneity of an embryo structure, such as the bending points of an embryonic surface, or the contact zones between the cells having the different size, may become the starting point for ESF formation (Fig. 2 F-I). Thus, any microscopic heterogeneity has an opportunity to be expressed at the macroscopic level as a change of shape of an embryo.

If the morphogenesis of a local ESF is based on self-organization, it should be governed by epigenetic factors. The question is: which factors from this set might be employed?

The morula cells, in contrast to the epithelial cells, do not possess any signs of definite polarity - they lack an apico-basal (AB) axis, structurally and functionally distinct surfaces (apical, basal and lateral ones) and the area of their contact zones is smaller than the area of their free surfaces (Fig. 2E). These cells are asymmetric in the sense that their contact zones are randomly distributed along the cell surface. It is known that any cell having at least punctate contact with its neighbor tends to increase the area of contact zone and the mechanism of this process has been recently studied (Yonemura et al., 1995; Ohno, 2001; Vasioukhin and Fuchs, 2001; Jamora and Fuchs, 2002). As a consequence, the cells establish or restore their polarity, creating a fragment of an epithelial cell layer. It is possible that the cells are driven to acquiring a highly polarized equilateral shape because such cells are mechanically equilibrated (Belintsev, 1991). Correspondingly, one may suggest that the morula cells are in the state of unstable equilibrium and any influence changing the properties of the cell surface can disturb its equilibrium and initiate the conversion of this cell into a properly equilibrated highly polarized state. In fact, epithelialization of morula cells starts in the regions where the formation of cell-cell contacts is

Fig. 3 (Top). The process of toroidal embryo formation (joining of epithelial sheet fragments). (A) Margins of two neighboring fragments, SEM data (LE , leading; TE, trailing edges of crawling cell). (B) The region framed in (A); arrows, filopodia). (C) The last step of joining of two neighboring ESFs. (D) Leading edge of the crawling cell, TEM data (cc, cell-cell contact zone; $y$, yolk granules; mv, microvilli; $f$, filopodia; L, lamella). Scale bars: A,C, $10 \mu \mathrm{m} ; D, 2 \mu \mathrm{m}$.

Fig. 4 (Bottom). Morphology of a toroidal embryo and the process of 'hole' closure by the crawling of epithelial cells. SEM data. (A) Toroidal embryo having three flat surfaces (two of them are visible), a 'hole' is situated in the center of each surface. (B) Half of the split of a toroidal embryo; the section passes through the 'hole' (ES, epithelial sheet). (C) The region framed by the rectangle in (B). Abbreviations: iec, inner epithelial cell; double arrow, apico-basal axis of epithelial crawling cell; oval frame, region of the zipping up of the hole margins. (D) The region marked by the asterisk in (C). as, apical surface of epithelial crawling cell. Scale bars: $A, B, 100 \mu \mathrm{m} ; C, D, 10 \mu \mathrm{m}$. 
impeded (for example, at the bending points of embryonic surface), so it is possible that it is the deficiency in cell-cell contact area which triggers the epithelialization.

The two-dimensional algorithm of epithelialization presented on the figure 5A has been reconstructed on the basis of histology, electron microscopy, morphometric and statistical analysis. We will trace the morphological transformations of cell II, which is one of two cells situated directly on the bending point of the embryonic surface. There is an obvious deficiency in the contact area between cells /-//(Fig 5A, step $/)$.

Cell // increases the length of contact zones between its 'left' lateral wall and cell I and between its 'right' lateral wall and cell //I. Cell //starts by extending its 'left' contact zone, which is extremely short. So, the initial cell's asymmetry, which was initiated by the heterogeneity of embryonic surface, is reinforced (Fig 5A, step 2). At the following steps of epithelialization (Fig. 5A, steps 2 - $M$ ) cell //becomes more and more polarized. The transformation of cell morphology looks more evident if we approximate the cell // at the different stages of epithelialization by quadrilateral planar figures (Fig. 5C). We find that, during epithelialization, the angle between the 'left' lateral wall and the apical surface $(\alpha \mathrm{L})$ differs from the angle between the 'right' lateral wall and the same cell apical surface $(\alpha R)$ (cells 2 and 3, Fig. 5C). The lengths of the 'left' and 'right' lateral walls of the same cell also are not equal to each other. The differences between the 'left' and 'right' angles and the 'left' and 'right' lateral walls gradually decrease with the progress of epithelialization (cf. cells 2, 3 and 4). Thus, a cell that is unilaterally perturbed by an external factor tends to come to the equilibrium (symmetric) state, but, by doing so, increases the asymmetry of its 'left' and 'right' sides. Under these conditions, in order to finally come to the symmetric state, a cell has to continue its transformation up to the equilateral state (Fig. 5A, step N, Fig. 5C, cell 4). Examples of cells passing through the different stages of epithelialization are presented in the figures $5 \mathrm{D}$ and $5 \mathrm{E}$. Cells in Figure 5D are strongly asymmetric, while the cell in Figure $5 E$ has a longer $A B$ axis that suggests it is close to the symmetrical state.

Cell // not only gradually increases the lengths

Fig. 5. Morphogenesis of local epithelial sheet fragments (ESFs). (A) Schematic drawing of a spatiotemporal sequence of cell shapes within a developing ESF. 1-N, steps of fragment epthelialization; I-V, cell numbers which correspond to the stages of cell epthelialization at step 4; double arrow, cell's apico-basal axis; as, apical; arrowhead, bending point of the embryonic surface; arrow, the direction of epithelialization spreading. (B) Drawings of histological sections of forming ESFs: bs, basal surface. (C) Changes in the cell shape, stages I-IV ( $L$, left; $R$, right lateral cell wall; $\alpha R$ and $\alpha L$, angles between the cell lateral wall and the cell apical surface). (D) Asymmetric cells at the beginning of epithelialization, SEM data and drawing (outlining of cells on the SEM picture) (Is, lateral cell surface). (E) Cell at the next stage of epithelialization, SEM data and drawing (outlining of cells on the SEM picture). Scale bars, $30 \mu \mathrm{m}$.

\section{A}

B of its lateral walls, but gradually rotates due to the changes in its shape and in the shape of the developing ESF (Fig. 5A). Changes in the shape of cell // affect the behavior of cell ///. The contact zone between the 'right' lateral wall of cell // and the 'left' lateral wall of cell /// becomes extremely small (Fig. 5A, step 2). This means that cell /// loses its equilibrium due to the morphological transformations of the neighboring cell directed towards the restoration of its own equilibrium. At this point cell /// becomes involved in the ESF. The subsequent shape changes of cell ///are identical with the shape changes of cell //described above. In a similar way, the cell $I V$ is involved in the epithelialization at the step 3 and so on. So, epithelialization is a process capable of active cell-to-cell spreading, i.e. it is really a self-organizing process. While it is a morphogenetic wave, since we have no evidence that the cells change kind in the process, it is not a differentiation wave (Gordon, 1999). The formation of an ESF is
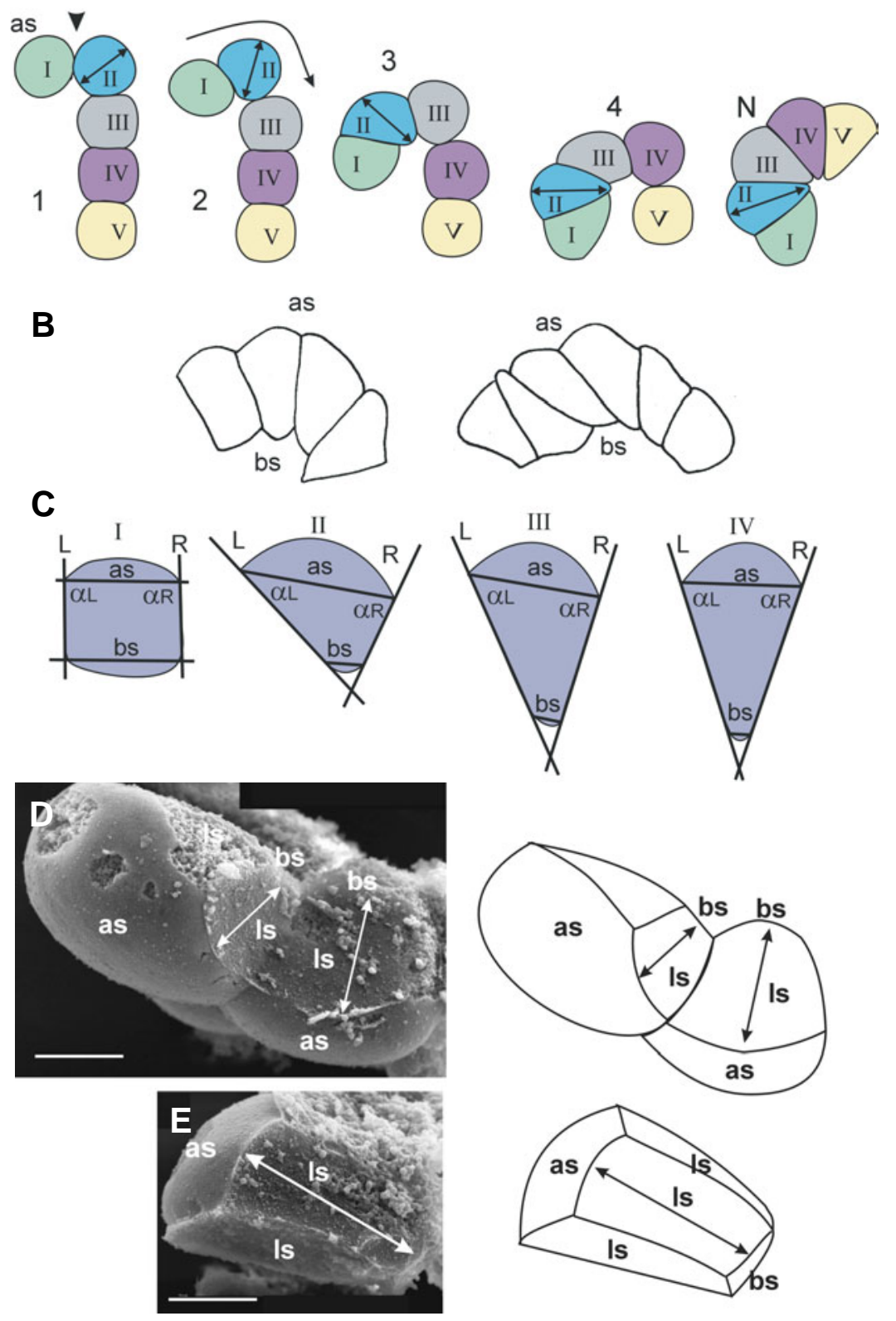


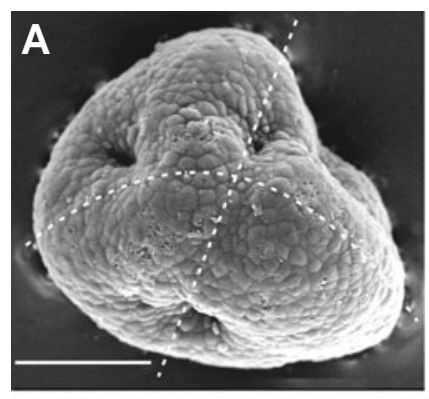

C
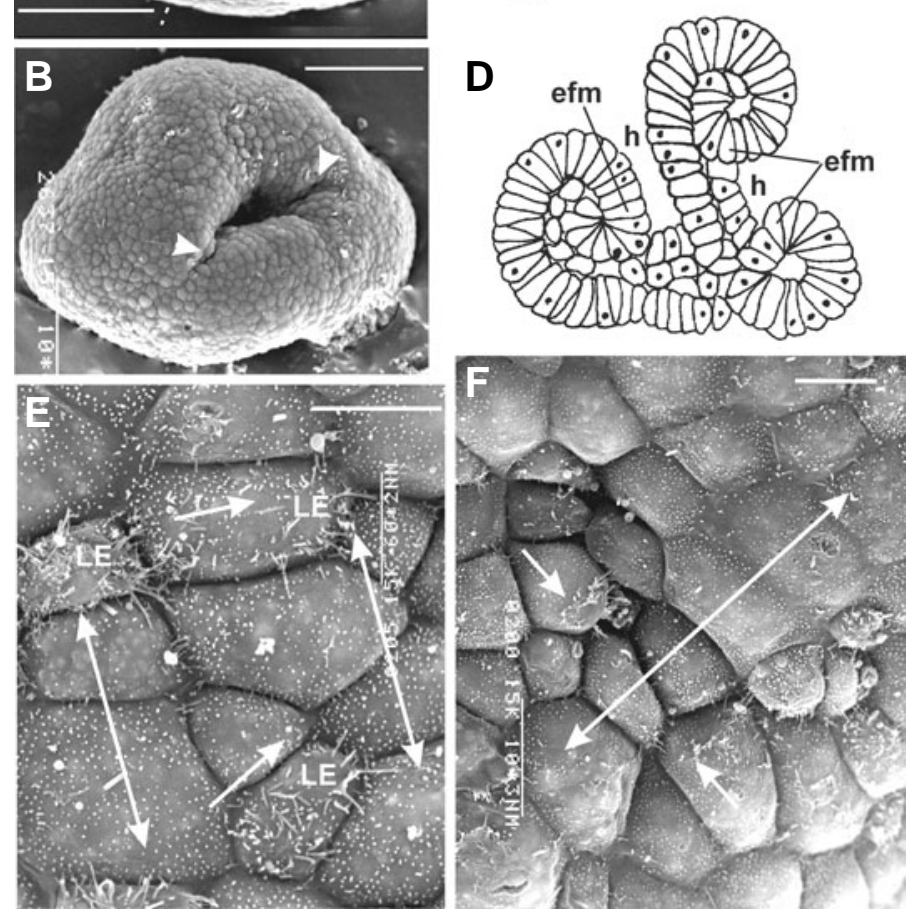

A

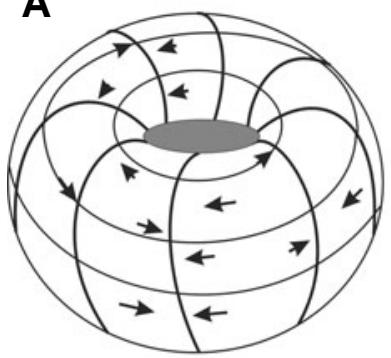

B

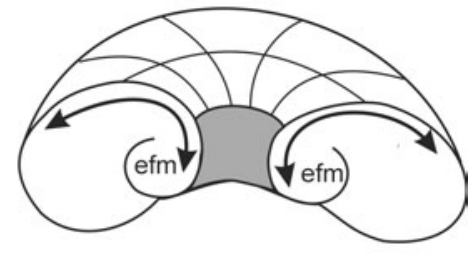

C
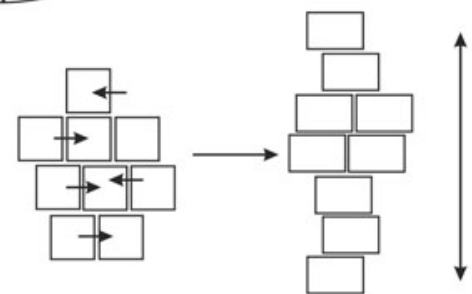

D

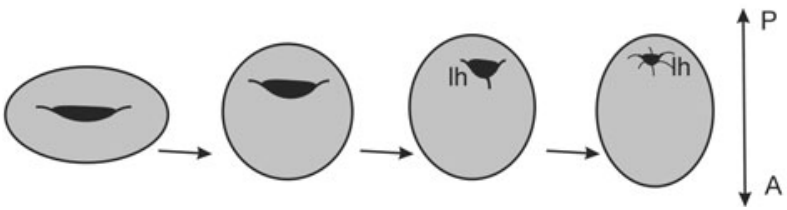

Fig. 6 (Left). Toroidal embryo. (A) An embryo at the toroidal stage having four flat surfaces (three of them are visible), SEM data. Dotted curve shows the plane of the section presented on (C), dotted line shows the plane of the section presented on (D). (B) An embryo at the toroidal stage having only two flat surfaces, SEM data (arrowheads, wrinkles forming at the 'hole' margin). (C) Schematic drawing of the latitudinal section of toroidal embryo. (D) Schematic drawing of the meridional section of an embryo passing through the 'holes' (h) (efm, enrolling free margins of epithelial sheet). (E,F) Coherent cell movements leading to changes in the shape of an embryo as a whole, SEM data (double-headed arrow, meridian of embryonic surface; arrow, direction of cell movement). Scale bars, A,B, $100 \mu \mathrm{m} ; E, F, 5 \mu \mathrm{m}$.

Fig. 7 (Right). Shaping of a toroidal embryo. (A) Schematic picture of a toroidal embryo (thick lines, meridians of an embryo, directions of the maximal stretching; thin lines, latitudes of an embryo; arrows, direction of cell movement). (B) Schematic drawing of the section passing through the meridian of a toroidal embryo (double-headed arrow, the direction of stretching which results from the rolling up of the epithelial sheet's free margin). (C) Scheme of cell movements (double-headed arrow, orientation of forming long axis). (D) Gradual changes in the shape of a toroidal embryo (Ih, last 'hole' of the embryonic surface).

terminated when all the cells involved in it become equilateral and the fragment as a whole becomes part of a circle (Figs. 2l;5A, step $M$. During epithelialization, the cells move, however, their displacements are not associated with the changes of their neighbors.

It is possible to conclude that ESF shaping, i.e. morphogenesis at the supracellular level, is only a side effect of a coherent selfreinforcing shaping of individual cells, each of them tending to reach the equilibrium (symmetric) state. Thus, the program of morphogenesis described above is contained in the morphogenesis itself - after the initiation of an ESF by a non-specific trigger, each step of cell shaping reorganizes the geometrical and mechanical conditions in such a way, that the next step of the cell and ESF transformations becomes inevitable. In the other words, there is a positive feedback between the shaping on the cellular and supracellular levels of this developing system. So, we can consider that the final shape of an ESF (a part of a circle) is preformed by cooperative epithelialization of the morula cells.
A correlation between the asymmetry of cells of embryonic Anlage and subsequent changes in the shape of this Anlage was found long ago by Gurwitsch (1922). He wrote that 'the configuration of embryonic Anlagen is dynamically preformed' by the cell shapes. Up to now the connection between the elements of asymmetry of a developing system and subsequent transformations of its shape has been found only in the morphogenetic events of the first type, when cells do not change their neighbors. The data on Dynamena early development has shown that this connection also works in the morphogenesis of the second type, which is based upon cell rearrangements.

\section{Shaping of toroidal embryos}

The active movements of Dynamena embryonic cells at the stage of local ESF formation are not concerted, i.e. there is no preponderant direction of cell displacement. However, this mode of cell behavior is very important for the formation of an integral 
superficial epithelial sheet having a toroidal shape (Figs. 4A;6 A, $B)$. At the latitudinal sections of embryos of this stage, we can find a continuous epithelial sheet (Fig. 6C). At the meridional section of an embryo we can see that the margins of a 'hole' corresponds to the free margins of the forming epithelial sheet (Figs. 6D, 7B). The SEM data shows that coherent cell movements start from this stage on. The long axes of cell apical surfaces are oriented along the latitudes and the cells move preponderantly towards meridians of toroidal surfaces (Fig. 6 E, F). This morphogenetic movement represents the process of planar intercalation of epithelial cells (Keller, 1987). The cell rearrangement leads to changes in the shape of an embryo as a whole - the meridians become longer while the latitudes become shorter (Fig. 7C, D). This means that the toroidal embryo should convert into the spherical one. However, in the case of real morphogenesis this is impossible. The spherical shape is dynamically unstable (Beloussov, 1996), i.e. any arbitrary fluctuation, which is a common occurrence in the course of normal morphogenesis, leads to the formation of an ellipsoid instead of a sphere (Fig. 7D, $8 \mathrm{~A})$. The major axis of an ellipsoid corresponds to the future anterio-posterior axis. So, coherent cell movements provide the first step of planula shaping: formation of its long axis.

Which mechanism governs this morphogenesis? We should take into account that a toroidal embryo acquires a closed epithelial sheet, providing mechanical integrity of the embryonic surface. This means that feedback between the cell position, shape of epithelial sheet and configuration of the field of mechanical stresses may originate at this stage. The experiments with cutting different regions of embryos and orientation of wrinkles which are formed at the 'hole' margin (Fig. 6B), demonstrate that the embryonic surface is indeed mechanically stressed at this stage and the direction of the maximal stretching coincides with the meridians of the toroidal embryo. This is the result of an active morphogenesis of the epithelial sheet free margins, which are involuted within the 'hole' of the toroidal surface (Fig. 7A, B). Since the cells are mechanically sensitive and their protrusive activity depends on their mechanical state (for example, see Raucher and Sheetz, 2000; Riveline et al., 2001), an imbalance of the latitudinal and the meridian mechanical stresses should trigger their displacement. Cells tend to move towards minimizing the disequilibrium of mechanical stresses existing in the epithelial sheet (Beloussov, 1998; Beloussov etal., 2000). This displacement is itself a coherent movement described above which converts a toroidal embryo into an ellipsoidal one. Each embryo consists of a set of flat surfaces with holes situated in their centers. Insofar as each hole has an individual rate of healing, the hole taking longer to heal than the others becomes the 'last hole' determining the direction of cell movements. Thus, the formation of an ellipsoidal embryo and the differentiation of the long axis of a planula are just sideeffects of the process providing the equilibration of the field of mechanical stresses on an embryonic surface. The morphology of an embryo at the toroidal stage determines the configuration of the field of mechanical stresses, which in its turn determines the direction of coherent cell movements and, thus, the geometry of an embryo at the next, i.e. ellipsoidal stage. In the other words, the shape of an ellipsoidal embryo is already preformed in the toroidal shape.

It is reasonable to note that two types of morphogenesis distinguished above, are successive stages of morphogenesis in Dynamena early development. Indeed, the formation of ESFs (morphogenesis of the first type) inevitably leads to shaping of the toroidal embryo (morphogenesis of the second type). Crawling activity of epithelial cells joining the ESFs provides a transitional step between these two stages.

\section{Conclusions}

1. Both the morphogenesis of a local ESF and the shaping of a toroidal embryo can be considered together as a cascade where a morphogenetic event is the result of a previous one. The spatial structure of each developmental stage implies that it has information on the direction and initial conditions of its own transformation and on the spatial structure of the next stage. This information can be interpreted as an 'epigenetic program' which gradually originates in the course of morphogenesis and provides the stable reproduction of spatial structure at any developmental stage. The epigenetic factors which govern Dynamena embryogenesis are: the general geometry (topology) of an embryo, an arbitrary heterogeneity of embryo spatial structure and the configuration of the field of mechanical stresses on the embryonic surface. Since all of these factors take part in the creation of the program of normal Dynamena development, it is reasonable to define their operation as 'morphomechanical programming' of morphogenesis.

2. Thus, in the case of Dynamena development, we do not need to assume any 'preexisting', detailed spatiotemporal program defining the structures which are formed at the successive developmental stages. Prior to the beginning of development, such a program does not exist at all. On the other hand, in order to get a reproducible result of development, we have to specify the initial conditions (the initial geometry of an egg cell, spatial distribution of the macromolecules, the yolk distribution and
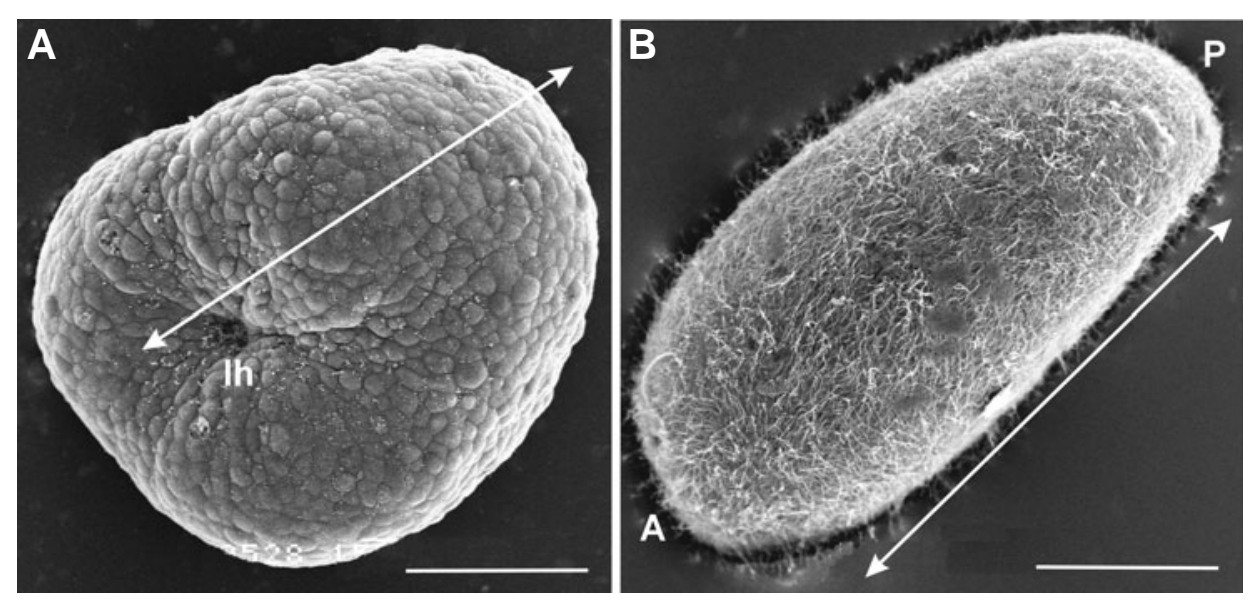

Fig. 8. Preplanula formation. (A) An ellipsoidal embryo (double arrow, long axis of an embryo, future axis of antero-posterior polarity). (B) Early planula stage (A and $P$, anterior and posterior poles). Scale bars, $100 \mu \mathrm{m}$. 
concentration, etc.) and the parameters (a set and properties of cytoskeleton, ion channel, intercellular contact and signaling molecules, etc.) of development.

3. From this point of view the 'genetic program' of embryogenesis should look much more like a set of the developmental parameters than a detailed schedule of developmental events.

\section{Materials and Methods}

Dynamenacolonies were collected at the White Sea Biological Station of Moscow State University during the reproduction season, in July August. Acrocysts were isolated from colonies and raised in filtered sea water at $14-16^{\circ} \mathrm{C}$. Embryos at successive developmental stages (from early cleavage up to planula formation) were prepared for light or electron microscopy.

The embryos prepared for light microscopy were fixed in $4 \%$ formaldehyde in filtered seawater. Fixed embryos were washed in filtered seawater and prestained in an ethanol solution of boric acid carmine. A series of paraffin sections (2-4 $\mu \mathrm{m}$ thickness) were prepared by the routine technique and poststained by alcian or toluidine blue. When preparing for SEM and TEM, we fixed the embryos in 2,5\% glutaraldehyde, in $0.1 \mathrm{M}$ cacodilic acid buffer $(\mathrm{pH} 7.2)$ and then postfixed them in $1 \%$ osmium tetroxide in the same buffer. Samples for SEM were dehydrated through a graded series of ethanol and then dried from acetone using the «critical point» technique. Samples were examined by S-405A (Hitachi) and CamScan microscopes. Samples for TEM were also dehydrated in ethanol and acetone and then embedded in Araldite embedding medium (Fluka), sectioned using routine technique, stained in a water solution of uranyl acetate and lead citrate and examined by transmission electron microscope JEOL JEM-1000B.

The detailed description of morphometrical and statistical analysis of the cell shapes is presented in Kraus and Cherdantsev (1995).

\section{Acknowledgments}

I thank all members of the Laboratory of Electron Microscopy of Moscow State University (G.N. Davidovich, A. G. Bogdanov, N. Zvonkova, M. Leontieva, A. Lazarev, N. Ya. Agalakova) for support and assistance and Prof. Lev V. Beloussov for support and fruitful discussions; the work was sponsored by the Russian Foundation for Fundamental Research (grants 02-04-49792, 04-04-48842) and the program 'Supporting of the Leading Research Teams (Scientific Schools)' (grant NSh-1825.2003.4).

\section{References}

ARNOLDS, W., VAN DEN BIGGELAAR, J. and VERDONK, N. (1983). Spatial aspects of cell interactions involved in the determination of dorsoventral polarity in equally cleaving Gastropoda and regulative abilities of their embryos as studied by micromere deletion in Lymnaea and Patella. W. Roux's Arch. Dev. Biol. 192: 75-85.

BELINTSEV, B.N. (1991). Fizicheskie Osnovy Biologicheskogo Formoobrazovaniya (Physical basis of biological morphogenesis). Nauka, Moskva (in Russian).

BELINTSEV, B.N., BELOUSSOV, L.V. and ZARAISKY, A.G. (1987). Model of pattern formation in epithelial morphogenesis. J. Theor. Biol. 129: 369-394.

BELOUSSOV, L.V. (1996). Patterns of mechanical stresses and formation of the body plans in animal embryos. Verh. Dtsch. Zool. Ges. 89: 219-229.

BELOUSSOV, L.V. (1998). The Dynamic Architecture of a Developing Organism. An Interdisciplinary Approach to the Development of Organisms. Kluwer Academic Publishers, Dordrecht.

BELOUSSOV, L.V., DORFMAN, J.G. and CHERDANTSEV, V.G. (1975). Mechanical stresses and morphological patterns in amphibian embryos. J. Embryol. Exp. Morphol. 34: 559-574.

BELOUSSOV, L.V., DORFMAN, J.G. and CHERDANTSEV, V.G. (1974). Rapid changes in form and cell architecture in isolated fragments of embryonic amphibian tissues as an experimental model of morphogenesis. Ontogenez (in
Russian). 5: 323-333.

BELOUSSOV, L.V., LOUCHINSKAIA, N.N. and STEIN, A.A. (2000). Tensiondependent collective cell movements in the early gastrula ectoderm of Xenopus laevis embryos. Dev. Genes Evol. 210: 92-104.

BELOUSSOV, L.V., SAVELIEV, S.V., NAUMIDI, I.I. and NOVOSELOV, V.V. (1994). Mechanical stresses in embryonic tissues: patterns, morphogenetic role and involvement in regulatory feedback. Int. Rev. Cytol. 150: 1-34.

CHERDANTSEV, V. G. (1977). The spatial unfoldings of morphogenetic movements as elements of the oral filed in Anurans. Ontogenez (in Russian). 8: 348360.

CHERDANTSEV, V.G., KRESLAVSKIY, A.G. and SEVERTSOV, A.S. (1996). Episelective evolution. Evolutionary Theory. 11: 69-87.

CHIQUET, M. (1999). Regulation of extracellular matrix gene expression by mechanical stress. Matrix Biol. 18: 417-426.

COFFMAN, J.A. and DAVIDSON, E.H. (2001). Oral-aboral axis specification in the sea urchin embryo. I. Axis entrainment by respiratory asymmetry. Dev. Biol. 230: $18-28$.

DAVIDSON, E. H., RAST, J. P., OLIVERI, P., RANSICK, A., CALESTANI, C., YUH, Ch.-H., MINOKAWA, T., AMORE G., HINMAN V., ARENAS-MENA C., OTIMO., BROWN C. T., LIVI C.B., LEE P.Y., REVILLA R., RUST A.G., jun PAN, ZH., SCHILSTRA, M. J., CLARKE, P. J. C., ARNONE, M. I., ROWEN, L., CAMERON, R.A., McCLAY D.R., HOOD L. and BOLOURI, H. (2002). A genomic regulatory network for development. Science. 295: 1669-1678.

EIZINGER, A., JUNGBLUT, B., SOMMER, R.J. (1999). Evolutionary changes in the functional specificity of genes. Trends Genet. 15: 197-202.

GALBRAITH, C.G. and SHEETZ, M.P. (1998). Forces of adhesive contacts affect cell function. Curr Opin Cell Biol. 10: 566-571.

GILBERT, S.F. (2001). Ecological developmental biology: developmental biology meets the real world. Dev. Biol. 233: 1-12.

GILBERT, S.F. and SARKAR, S. (2000). Embracing complexity: organicism for the 21st Century. Dev Dyn. 219, 1 - 9.

GOODWIN, B. C. (2000). The life of form. Emergent patterns of morphological transformation. C. R. Acad. Sci. 323: 15-21.

GORDON, R. (1999). The Hierarchical Genome and Differentiation Waves: Novel Unification of Development, Genetics and Evolution. World Scientific \& Imperial College Press, Singapore \& London.

GRBIC, M. (2000). 'Alain' wasps and evolution of development. Bioessays. 22: 920932.

GURWITSCH, A. G. (1922). Der Vererbungsmechanismus der Form. Arch. fur Entwicklungsmechaniks. 39: 516-577.

JACINTO, A. and MARTIN, P. (2001). Morphogenesis: Unravelling the cell biology of hole closure. Curr Biol. 11: 705-707.

JAMORA, C. and FUCHS, E. (2002). Intercellular adhesion, signalling and the cytoskeleton. Nat Cell Biol. 4: 101-108.

KELLER, R. (1987). Cell rearrangement in morphogenesis. Zool. Sci. 4: 763-779.

KELLER, R., DAVIDSON, L. and SHOOK, D. (2003). How we are shaped: The biomechanics of gastrulation. Differentiation. 71: 171-205.

KIEHART, D. P., GALBRAITH, C. G., EDWARDS, K. A., RICKOLL, W. L. and MONTAGUE, R. A. (2000). Multiple forces contribute to cell sheet morphogenesis for dorsal closure in Drosophila. J. Cell Biol.149: 471-490.

KIRWAN, R.P., CREAN, J.K., FENERTY, C.H., CLARK, A.F. and O'BRIEN, C.J. (2004). Effect of cyclical mechanical stretch and exogenous transforming growth factor-beta1 on matrix metalloproteinase-2 activity in lamina cribrosa cells from the human optic nerve head. J. Glaucoma. 13: 327-334.

KRAUS, Yu.A. and CHERDANTSEV, V.G. (1995). Primary epithelialization of cells during the early development of a marine hydroid polyp, Dynamena pumila L. Russ. J. Dev. Biol. (Ontogenez). 26: 223-230.

KRAUS, Yu.A. and CHERDANTSEV, V.G. (1999). Variability and equifinality in the early morphogenesis of marine hydroid Dynamena pumila. Russ. J. Dev. Biol. (Ontogenez) 30: $118-129$.

KRAUS, Yu.A. and CHERDANTSEV, V.G. (2003). Experimental study of AP axis formation in the early development of marine hydroid Dynamena pumila. Russ. J. Dev. Biol. (Ontogenez). 36: 365-378.

KROPF, D.L., BISGROVE, SH.R. and HABLE, W.E. (1999). Establishing a growth 
axis in fucoid algae. Trends Plant Sci. 4: 490-494.

MARTIN, P. and PARKHURST, S. M. (2004). Parallels between tissue repair and embryo morphogenesis. Development. 131: 3021-3034.

MARTIN-BLANCO, E. and KNUST, E. (2001). Epithelial morphogenesis: Filopodia at work. Curr Biol. 11: 28-31.

METSHNIKOFF, E. (1886). Embryologische studien an Medusen. Ein Beitrag zur genealogie der Primitiv-organe. Alfred Holder, Vienna.

NEWMAN, S.A. and MULLER, G.B. (2000). Epigenetic mechanisms of character origination. J. Exp. Zool. 288: 304-317.

OHNO, Sh. (2001). Intercellular junctions and cellular polarity: the PAR-aPKC complex, a conserved core cassette playing fundamental roles in cell polarity. Curr Opin Cell Biol. 13: 641-648

OSTER, G.F., MURRAY, J.D. and HARRIS, A.K. (1983). Mechanical aspects of mesenhimal morphgenesis. J. Embryol. Exp. Morph. 78: 83-125.

RAFF, R. (1996). The Shape of Life. University of Chicago Press, Chicago.

RAUCHER, D. and SHEETZ, M. P. (2000). Cell spreading and lamellipodial extension rate is regulated by membrane tension. J. Cell Biol. 148: 127-136.

RIVELINE, D., ZAMIR, E., BALABAN, N. Q., SCHWARZ, U. S., ISHIZAKI, T., NARUMIYA S., KAM, Z., GEIGER, B. and BERSHADSKY, A. D. (2001). Focal contacts as mechanosensors: externally applied local mechanical force induces growth of focal contacts by an mdia1-dependent and ROCK-independent mechanism. J Cel/ Biol. 153: 1175-1185.

STROHMAN, R. (2002). Maneuvering in the complex path from genotype to phenotype. Science. 296: 701-703.

TIAN, J., ISHIBASHI, K. and HANDA, J.T. (2004). The expression of native and cultured RPE grown on different matrices. Physiol. Genomics. 17: 170-182.

VASIOUKHIN, V. and FUCHS, E. (2001). Actin dynamics and cell-cell adhesion in epithelia. Curr Opin in Cell Biol. 13: 76-84.

VASIOUKHIN, V., BAUER, C., YIN, M. and FUCHS, E. (2000). Directed actin polymerization is the driving force for epithelial cell-cell adhesion. Cell. 100: 209-219.

WILKINS, A. (2001). Evolution of developmentalpathways. Sinauer, Massachusets Inc.

WRAY, G. A. and ABOUHEIF, E. When is homology not homology? (1998). Curr Opin Genet Dev. 8: 675-680.

WU, Q., ZHANG, Yu. and CHEN, Q. (2001). Indian hedgehog is an essential component of mechanotransduction complex to stimulate chondrocyte proliferation. J. Biol. Chem. 276: 35290-35296.

YONEMURA, Sh., ITOH, M., NAGAFUCHI, A. and TSUKITA, S. (1995). Cell-to-cell adherens junction formation and actin filament organization: similarities and differences between non-polarized fibroblasts and polarized epithelial cells. J. Cell Sci. 108: 127-142. 